\title{
O DESENVOLVIMENTO DAS HISTÓRIAS EM QUADRINHOS NO BRASIL
}

\author{
Santos, I. G. R. B. De A.; Cruz, T. A. da; Horn, M. L. V.;
}

\section{RESUMO}

0 design, como comunicador de conceitos e ideias, frequentemente utiliza a linguagem dos quadrinhos em muitos de seus trabalhos. 0 presente artigo faz uma pesquisa básica, por meio de uma revisão bibliográfica e documental descritiva, sobre a história do aparecimento e desenvolvimento das histórias em quadrinhos no Brasil, desde sua primeira produção no país em 1867 até as publicações nacionais contemporâneas. A pesquisa ainda é ilustrada por imagens das obras mais importantes e influentes, retiradas bancos de imagens históricas sobre o tema na Internet. E o objetivo de apresentar os quadrinhos através dos tempos é poder melhorar o embasamento e a compreensão desta linguagem, ao aproximar o design do desenvolvimento da narrativa gráfica e do contexto histórico dos quadrinhos, para que o designer possa utilizar os recursos das narrativas gráficas de uma forma mais consciente e contextualizada na expressão de projetos.

Palavras chave: história em quadrinhos, história, design e quadrinhos.

\section{ABSTRACT}

Design, as a communicator of concepts and ideas, often uses the language of comics in many of its works. This article is a basic research based on a literature and documental review about the history of comics and its development in Brazil, since its first national production in 1867 to the contemporary publications. The research is illustrated by images of the most important and influential works. These images were taken from databases of comics on the Internet. And for presenting comic books through time the aim is to improve the fundamentals and understanding of this language, when approaching design to the comics graphic narrative development and historical context. Thus the designer can use the features of the graphic narratives in a more conscious and contextualized way in the expression of his/her projects.

Key-words: comics, comics history, design and comics.

\section{INTRODUÇÃO}

As histórias em quadrinhos, ou simplesmente HQs, com seus elementos visuais e textuais, somado ao seu modo leitura particular têm sido aplicadas pelo design, principalmente nos últimos anos. O design, muitas vezes, apropria-se de suas narrativas gráficas como linguagem, o que amplia suas formas de comunicação pelas quais pode transmitir conteúdo.

Além dos tradicionais quadrinhos de heróis e personagens infantis, as HQs são utilizadas para a comunicação dos mais variados interesses. Assim, por exemplo, como a retratação de eventos históricos e o 
registro de eventos recentes como a transcrição dos relatórios técnicos da investigação do atentado de 11 de setembro em Nova York em quadrinhos. Esta linguagem facilita a compreensão pelo público em geral (figura 1), como manuais de instrução e utilização, além de publicidade de produtos e serviços. Um bom exemplo é o manual de uso do navegador Web do Google, o Google Chrome (figura 2). Outros exemplos são encontrados como peças publicitárias como a campanha da Adidas do melhor time de futebol do mundo formado por seus atletas patrocinados (figura 3). Também na educação, como livretos, revistas educacionais, dentre outros aplicam as histórias em quadrinhos. Conforme apontado por McCloud (2004), os quadrinhos possuem possibilidades ilimitadas, seja no momento da criação pelo quadrinista quanto no momento da interpretação pelo leitor.

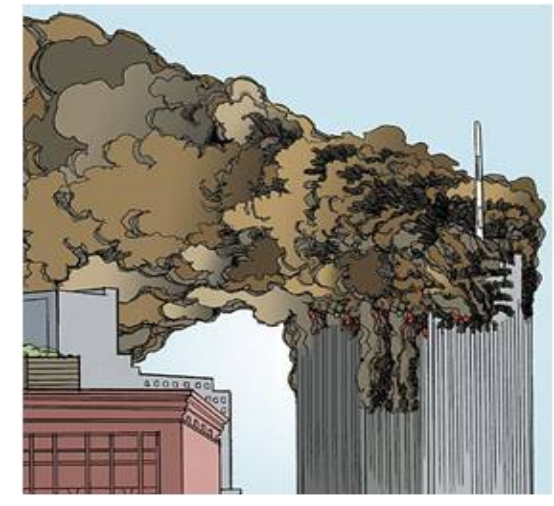

Figura 01 - Quadro da revista The 9/11 Report: A Graphic Adaptation

Fonte: Minzesheimer, 2006

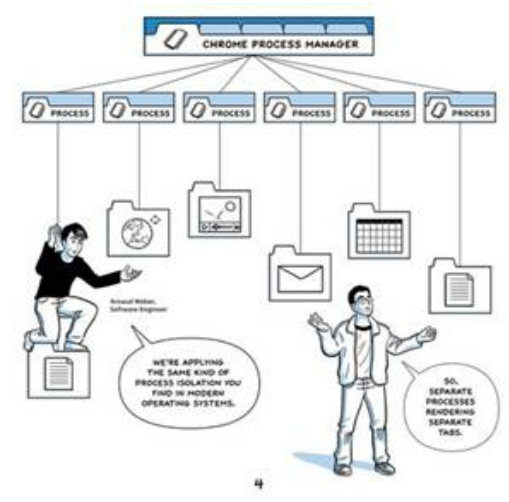

Figura 02 - Quadro do manual de utilização do Google Chrome

Fonte: Google Chrome Team, 2011

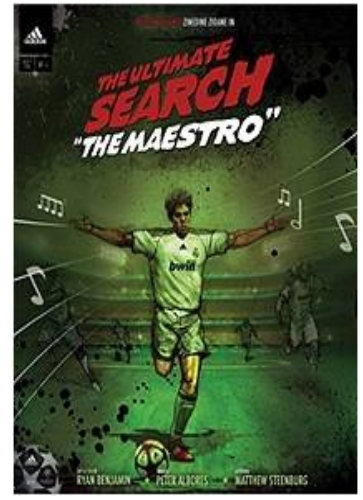

Figura 03 - Capa da Revista da Adidas

Fonte: Adidas Football, 2011.

O design, antes considerado restrito ao desenvolvimento de produtos e peças gráficas, vem ganhando espaço em outras aplicações, como o desenvolvimento de serviços e entretenimentos. De forma simplificada, seu processo de criação pode ser descrito como a abordagem de um problema tendo a visão de um designer, focado "no desenvolvimento de soluções impecáveis esteticamente e com novas funcionalidades, criando novas experiências, valor e, principalmente, significado para os consumidores" (BOER e BONINI, 2010). Partindo desse princípio, o design, com suas ferramentas e métodos, é um instrumento direcionado à criação de soluções que mais se adéquam às necessidades do ser humano.

Para a produção de uma HQ, o foco no leitor, buscando suas necessidades e desejos, e ao mesmo tempo, a necessidade de passar a mensagem desejada é, num âmbito comparativo, o mesmo foco que a produção de uma peça de design deve ter ao realizar um projeto. A construção de uma história em quadrinhos faz uso de ferramentas semelhantes às do design. Enquadramento da fala, seleção de elementos do requadro, roteirização, entre outras características, têm como objetivo central o leitor, no caso, o "consumidor" do autor. Segundo Eisner (2005, p. 51):

"Para quem você está contando sua história? A resposta a essa pergunta precede o próprio ato de contar uma história porque é uma preocupação fundamental da transmissão. 0 perfil do leitor - sua experiência e características culturais - tem de ser levado em conta antes que o narrador possa contar a história com sucesso". 
O encontro entre design e as histórias em quadrinhos não está somente na preocupação com o "cliente" ou em seus métodos de criação e produção. Ambas as atividades se preocupam com a organização e a disposição de imagens e textos, o meio, para que o fim, a mensagem passada seja compreendida pelo leitor.

Além disso, o design faz uso das ferramentas das HQs em diversos momentos, como por exemplo, na criação de storyboards para o desenvolvimento de produtos e serviços, usando transição de quadros em forma sequencial para ilustrar o que se necessita, ou ainda, na determinação da movimentação dos olhos durante a leitura de uma peça gráfica.

E, não raro é encontrar leitores, ilustradores e entusiastas dos quadrinhos dentro dos cursos de design em todo o país. Visto que não há um curso superior específico para a indústria de HQs, o design muitas vezes se mostra uma opção interessante, como forma de aprendizado, para aqueles que desejam estudar e ingressar nesta área.

Para a ADG, Associação dos Designers Gráficos, “O design gráfico é um processo técnico e criativo que utiliza imagens e textos para comunicar mensagens, ideias e conceitos, com objetivos comerciais ou de fundo social" (ADG, 2011). Esta definição poderia também ser aplicada ao processo técnico na criação de quadrinhos. Entretanto, Eisner (2005) classifica os quadrinhos como uma forma de expressão artística e literária. Contudo, a utilização dos quadrinhos, não como arte, mas sim como forma de transmissão de informação, pode, e muitas vezes é utilizada pelo design. Assim, cabe dizer que há uma intersecção entre essas atividades distintas, onde ambas podem colaborar entre si para alcançar um objetivo.

Partindo desse pressuposto, o levantamento histórico com a demonstração do desenvolvimento e das mudanças ocorridas ao longo do tempo pelas histórias em quadrinhos pode contribuir para o seu entendimento enquanto possibilidade como linguagem atual e contemporânea para o design.

\section{METODOLOGIA DA PESQUISA}

Neste estudo são identificados autores e obras que, no Brasil, contribuíram significativamente para transformação e desenvolvimento das HQs, desde sua primeira produção nacional até aquelas produzidas atualmente. A fim de proporcionar um maior conhecimento sobre as histórias em quadrinhos no país, realizou-se uma pesquisa sobre o tema principal, abordando suas características, sua contextualização e sua história, bem como sua inserção e desenvolvimento no Brasil, além de seu atual estado no país. E para exemplificar são apresentadas algumas capas das revistas e figuras mais importantes de cada época.

A natureza da pesquisa é básica, visa gerar um maior conhecimento a respeito das HQs, mas sem o desenvolvimento de uma aplicação prática prevista. 0 problema é abordado de forma qualitativa e possui o objetivo de descrever através de uma pesquisa bibliográfica e documental o desenvolvimento brasileiro das HQs em quadrinhos (GIL, 1991). 


\section{HISTÓRIAS EM QUADRINHOS}

O homem, como a maioria dos animais, se comunica com outro da mesma espécie. 0 que distingue a humanidade é sua diversificação comunicacional. Desde a idade da pedra existem os contadores de histórias e, para ilustrar o que falavam, estes faziam uso de sons, gestos e, finalmente, imagens (EISNER, 2005).

Essas imagens auxiliavam o contador de história a se fazer entender mais claramente, vide que representavam elementos reconhecíveis pelos espectadores. Depois veio o sequenciamento, onde várias imagens justapostas representavam uma determinada ação (EISNER, 2006). Essa é apenas uma das prováveis origens dos quadrinhos, assunto esse ainda indefinido e motivo de discussão dos teóricos.

0 termo "história em quadrinhos" é descrito pelo Dicionário Houaiss da Língua Portuguesa como "sequência de desenhos, geralmente com diálogos em balões, que contam uma história". E em seu História e Crítica dos Quadrinhos Brasileiros, Cirne busca definir história em quadrinhos a partir de sua formação:

"o que são quadrinhos? Para nós, a „banda desenhada" forma-se com um agenciamento/desencadeamento de imagens que se estruturam e se articulam a partir de cortes espaciais e temporais (cortes gráficos), gerando um tempo narrativo" (1990, p.13).

Ainda buscando uma definição completa para o termo, pode-se verificar McCloud, que procura, a partir de uma série de conclusões sobre a formação de uma história em quadrinhos, conceituar que quadrinhos são: "Imagens pictóricas e outras, justapostas (colocadas lado a lado) em sequência deliberada, destinadas a transmitir informações e/ou produzir uma resposta no espectador" (2004, p. 9).

Completa-se o entendimento de história em quadrinhos verificando que esse meio de comunicação faz uso dos dois tipos de linguagem humana: verbal e não-verbal. A primeira utiliza vocábulos presentes no idioma vigente para expressar informação. A segunda utiliza tanto imagens quanto gestos para expressar informação; sendo a decodificação de ambas as linguagens considerada leitura (EISNER, 2006).

\subsection{ORIGEM E DESENVOLVIMENTO DOS QUADRINHOS}

A origem dos quadrinhos é uma incógnita e afirmá-la é algo tentado por teórico e estudiosos de história em quadrinhos há muito tempo. Como conhecemos atualmente, seguindo as características descritas no tópico anterior, pode ser apontada sua origem como europeia, mas precisamente na França, em 1827 pelo suíço Rodolphe Töpffer, autor de “M. Vieux-Bois” (figura 4), sendo elogiado por Goethe, escritor e pensador ícone da literatura alemã, tendo este se tornado o primeiro crítico de HQs (MOYA, 1996). Já a primeira história em quadrinhos colorida e com balões foi "Down Hogan's Alley", (figura 5) conhecida no Brasil como "O menino amarelo", de Richard Outcault, em 1895. 


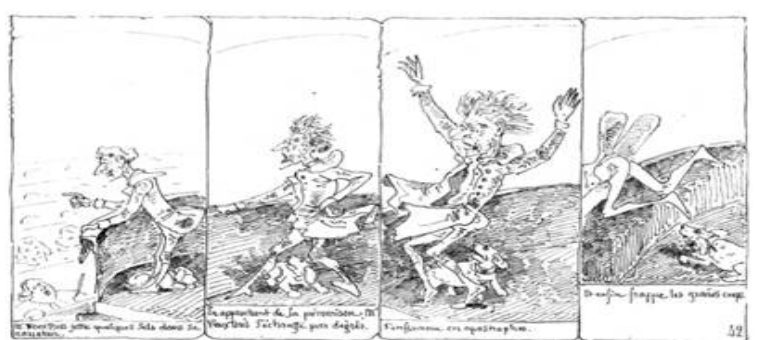

Figura 04 - Tirinha de M. Vieux-Bois:

Fonte: Michigan State University Libraries

Digital \& Multimedia Center, 2011.

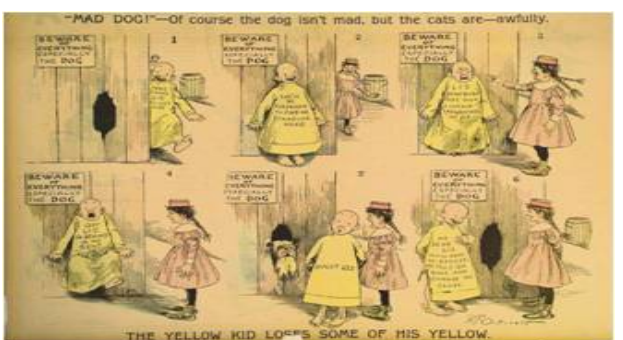

Figura 05 - Down Hogan's Alley

Fonte: San Francisco Academy of Comic

Art Collection

Em seus primórdios como comunicação de massa, os quadrinhos foram desenvolvidos como tiras de jornal ou tirinhas, definido pelo Dicionário Houaiss da Língua Portuguesa como "fragmento de história em quadrinhos, apresentado numa só faixa horizontal". Depois vieram os suplementos dominicais, onde o formato tablóide ( 43 × $28 \mathrm{~cm}$, aproximadamente), de origem inglesa, formou a segunda geração de quadrinhos (JUNIOR, 2004).

A necessidade de desenvolvimento de histórias completas, não permitidas pelas tirinhas pelo seu tamanho reduzido, de três a quatro quadrinhos, e nem pelos suplementos dominicais deu origem às revistas em quadrinhos em seus formatos tradicionais de $17 \times 26 \mathrm{~cm}$, conhecido como formato americano, e 13,5 x 9 $\mathrm{cm}$, chamado de formatinho, muito comum no Brasil. A sofisticação das revistas deu origem às graphic novels, traduzidas literalmente como novelas gráficas, revistas com histórias completas e com conteúdo mais sério (EISNER, 2005).

O desenvolvimento das HQs no mundo transcorre, como em qualquer outro meio de comunicação, de acordo com as mudanças socioculturais dos países, conforme dito por Coupèrie (apud BRAGA JUNIOR, 2005, p.22): “A relação das histórias em quadrinhos com a realidade é bem complexa. No todo, a história em quadrinhos é verdadeiramente uma testemunha de seu tempo e tudo pode ser encontrado nela".

Sendo assim, verifica-se que, diferente de outros meios de comunicação, como o cinema, que teve uma única origem, as histórias em quadrinhos, com seus "nascimentos" regionais, tomou caminhos bem diferentes.

\subsection{HISTÓRIA EM QUADRINHOS NO BRASIL}

O precursor dos quadrinhos no Brasil, chamados na época de historietas em quadrinhos, ou simplesmente historietas, termo apropriado da língua espanhola (JUNIOR, 2004), foi Ângelo Agostini, um italiano radicado no Brasil. Em 1867, cinco anos após chegar ao país, Agostini começou a trabalhar como desenhista na revista "Diabo Coxo". E neste ano, produziu sua primeira história em quadrinhos, "As 
Cobranças”, para a revista “O Cambrião” (MOYA, 1997).

A produção nacional juntou-se com adaptação de quadrinhos importados, na revista "O Tico-Tico" (figura 06), lançada no ano de 1905, pelo mesmo Ângelo Agostini. A revista misturava passatempos, educação, contos e quadrinhos, como Chiquinho, baseado diretamente no personagem Buster Brown, onde os desenhos eram decalcados dos originais americanos e os roteiros adaptados à realidade brasileira (BARBOSA, 2006).

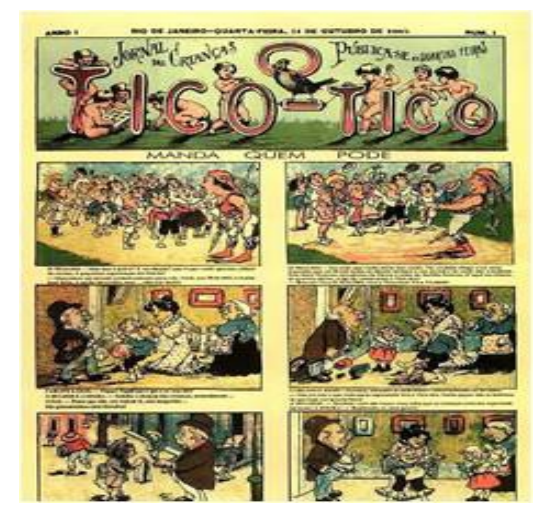

Figura 06 - Página do Almanaque Tico-tico

Fonte: Miranda, 2011

O ramo editorial descobriu o potencial dos quadrinhos de massa quando um ainda jovem Roberto Marinho, fundador das Organizações Globo, enviou um de seus repórteres, Adolfo Aizen, fundador da Ebal, Editora Brasil-América para uma empreitada aos Estados Unidos, no que foi chamado de Cruzeiro Turístico e Cultural a América do Norte, no ano de 1933. Nessa viagem, patrocinada pelos clubes de turismo norteamericanos para estimular a ligação entre os países das Américas, Aizen teve seu primeiro contato com as revistas de quadrinhos, ficando fascinado pelo formato e pelas histórias, trazendo a ideia para o Brasil e para Roberto Marinho. Marinho não lhe deu muita atenção, porém Aizen, sem se dar por vencido, levou sua novidade para o capitão João Alberto Lins de Barros, chefe de polícia do governo de Getúlio Vargas e diretor do jornal "A Nação". João Alberto não só gostou da ideia, como fez um suplemento para cada dia útil da semana, seguindo o modelo norte-americano de comic book, a revista de histórias em quadrinhos propriamente dita (JUNIOR, 2004).

As tirinhas e os suplementos de jornais faziam muito sucesso entre crianças e jovens, e isso não passou despercebido por Marinho. Após os lançamentos de Aizen, "Suplemento Juvenil” e "Mirim”, Marinho lançou o "Globo Juvenil" e "Gibi" (figuras 07 e 08), termo que se tornou sinônimo de revista em quadrinhos no Brasil (CAMARGO, 2003). Enquanto nos produtos de Aizen haviam histórias e passatempos de artistas nacionais e estrangeiros, Marinho optou por ter apenas material estrangeiro. Nessa mesma época, um ainda desconhecido Nelson Rodrigues, fazia adaptações de obras clássicas, como “O Fantasma de Canterville”, de Oscar Wilde. 


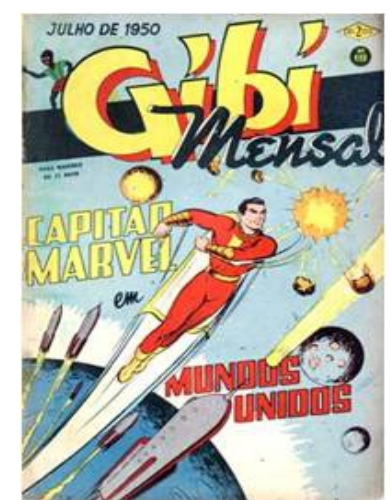

Figura 07 - Capa da revista Gibi com o Capitão Marvel Fonte: Gibiosfera, 2010

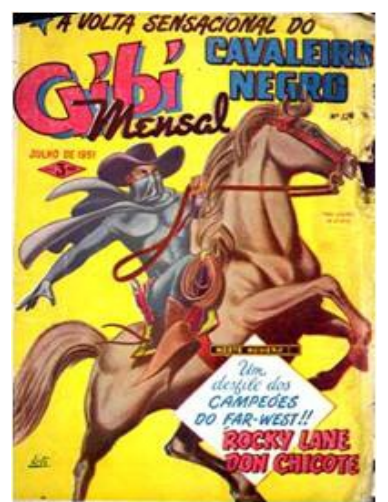

Figura 08 - Capa da revista Gibi com Cavaleiro Negro

Fonte: Gibiosfera, 2010

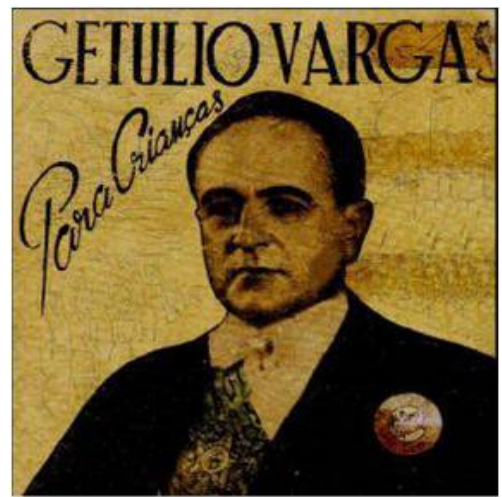

Figura 09 - Getúlio Vargas para Crianças

Fonte: Ferreira; Fernandes, 2004

Assis Chateubriand, conhecido magnata das comunicações entre as décadas de 1930 e 60, também investiu nas HQs, criando a revista "O Gury" em 1940. Nessa mesma época, os primeiro ataques por parte de jornalistas e religiosos eram desferidos contra as histórias em quadrinhos, acusando-as de instigar a delinquência juvenil (JUNIOR, 2004). Aizen defendia suas publicações mantendo sempre contato com o Palácio Guanabara, sede do governo federal na época, e publicando histórias como Ruy Barbosa para Crianças e Getúlio Vargas para Crianças (figura 09). Roberto Marinho foi quem mais sofreu ataques, pois suas publicações eram em sua maioria importadas, e Orlando Dantas, editor do jornal Diário de Notícias, foi seu maior algoz. Com o apoio de religiosos, que recebiam aval de Roma para tal perseguição, iniciou uma série de editoriais e reportagens de capa contra a leitura de quadrinhos. Por sua vez, Marinho utilizava seu jornal O Globo para se defender (RABELO, VIRTUOSO, 2008).

Gilberto Freyre, escritor e sociólogo, com mandato de deputado federal no ano de 1948 saiu em defesa das HQs apontado-as como uma ferramenta importante de comunicação e educação. Enquanto isso, Carlos Lacerda, outro parlamentar, se posicionou contra (JUNIOR, 2004).

Nos anos de 1950, Victor Civita, imigrante italiano, juntamente com seu irmão que já morava na Argentina, César Civita, lançam a Editora Abril. A editora La Selva começa a publicar HQs de terror, instigando ainda mais a discussão sobre o papel das histórias na mente das crianças e jovens. Em 1951, numa iniciativa da chamada "turma da La Selva" (Jayme Cortez, Miguel Penteado, Reinaldo de Oliveira, Silas Roberg e Álvaro de Moya), nasce a Primeira Exposição Didática Internacional de Histórias em Quadrinhos. Os curadores do MASP, Museu de Arte de São Paulo, Pietro Maria Bardi e Lina Bo Bardi, recusaram o pedido de receber a exposição, dizendo não se tratar de arte (JUNIOR, 2004), porém, no último dia da exposição, que aconteceu no Centro Israelita, ambos foram prestigiar o evento e ao fim disseram ter mudado de ideia com relação às histórias em quadrinhos. Era a primeira exposição sobre o tema do mundo. E no mesmo ano Roberto Marinho lançava a RGE, Rio Gráfica Editora (MOYA, 1994).

Um movimento de nacionalização dos quadrinhos tomou forma nos anos 1950. Primeiro com a 
proposta de uma reserva de mercado (leia-se porcentagem publicada em cada revista) de $2 / 3$ e depois de $75 \%$, pretendia-se assim proteger e incentivar o profissional brasileiro. As editoras eram contra, pois diziam que os originais brasileiros eram mais caros que os importados. E os ataques cada vez mais aumentavam, por isso, houve uma espécie de evangelização dos quadrinhos. Aizen e outros editores começaram a publicar histórias bíblicas e religiosas e, ao mesmo tempo, publicava literatura nacional e temas educacionais em forma de HQ, como por exemplo, "Série Sagrada” (figura 10), “Grandes Figuras em Quadrinhos” (figura 11), “Ciência em Quadrinhos" (figura 12) e "Edição Maravilhosa” (JUNIOR, 2004).

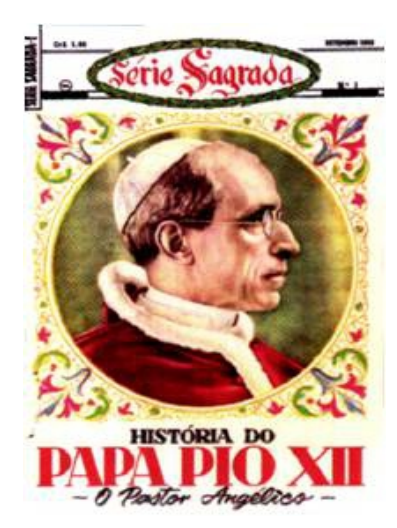

Figura 10 - Capa da Série Sagrada

Fonte: Guia Ebal, 2001

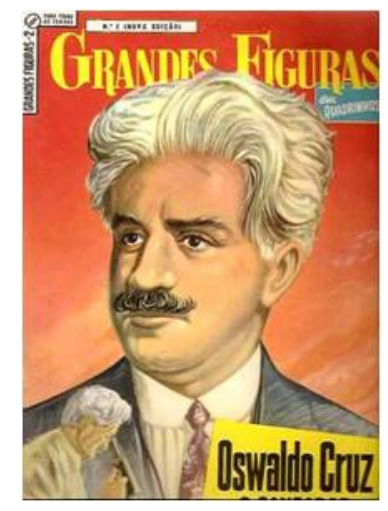

Figura 11 - Capa das grandes

Figuras

Fonte: Guia Ebal, 2001

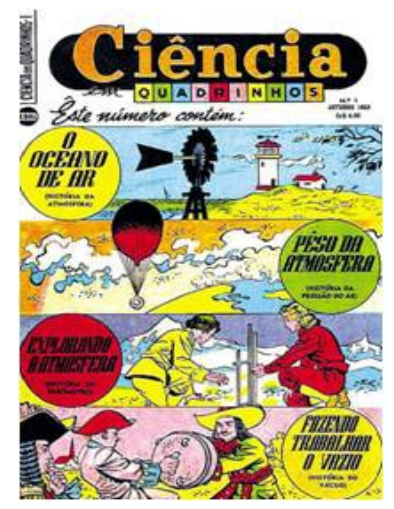

Figura 12 - Capa da ciência em Quadrinhos

Fonte: Guia Ebal, 2001

Também nos anos de 1950, três publicações de enorme importância tiveram início. "Os Catecismos" (1950), de Carlos Zéfiro (figura 13), quadrinhos com conteúdo pornográfico, vendidos praticamente na ilegalidade, causaram um grande frisson entre os jovens e os inimigos dos quadrinhos e durou cerca de 30 anos. "Pererê" (1959) de Ziraldo (figura 14), além do personagem folclórico, apresentava uma série de outras figuras da cultura brasileira, com desenhos estilizados e, com seu sucesso, aumentou ainda mais o movimento de nacionalização dos quadrinhos. A outra criação foi “Bidu” (1959) de Maurício de Sousa (figura 15). Precursor de uma série de outros personagens, o cãozinho teve sua primeira tirinha publicada pela Folha de São Paulo, "inaugurando a galeria de tipos de Maurício que viria a ser absoluto criador de maior resposta popular no Brasil, com merchandising, revistas, tiras de jornal (em distribuição e estilo norteamericano), televisão, cinema, publicidade e brinquedos...” (MOYA, 1996, pg. 177). 


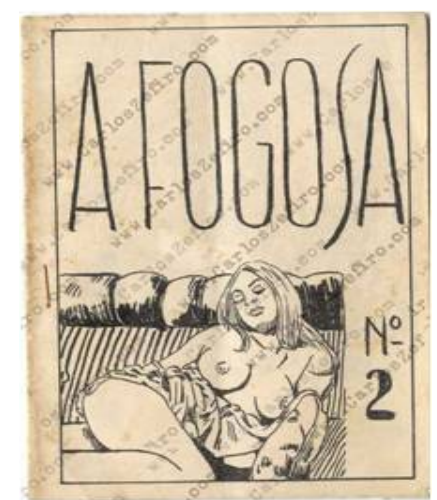

Figura 13 - Capa de Catecismos

Fonte: O Mundo de Carlos Zéfiro, 2011

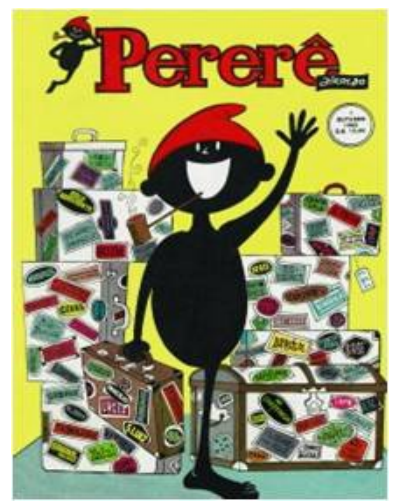

Figura 14 - Capa de Pererê

Fonte: MAGNO, 2010

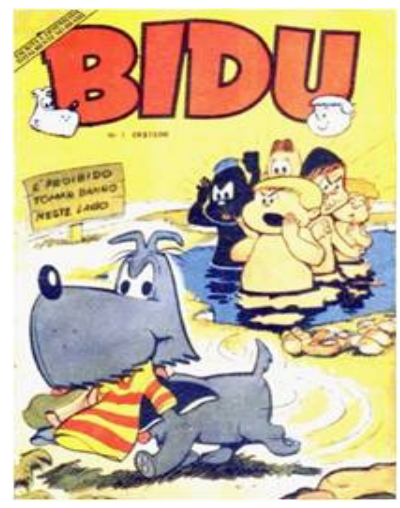

Figura 15 - Capa de Bidu

Fonte: SOUZA, 2001

No começo dos anos 1960 as duas HQs mais vendidas da RGE eram produzidas no Brasil: "Jerônimo, o Herói do Sertão", de Moisés Weltman e de Edmundo Rodrigues e "As Aventuras de O Anjo", de Álvaro de Aguiar e Flávio Colin. Veio também o código auto-regulamentador brasileiro, proposto pelos maiores editores da época. Jânio Quadros, presidente da república, desde seus tempos de governador de São Paulo, perseguia as histórias em quadrinhos, seguindo suas propostas moralistas. Cerca de 20 milhões de exemplares eram vendidos por mês, entre títulos com histórias brasileiras e importadas.

Muitos personagens surgiram nessa época, alguns baseados em estrangeiros, outros bem originais. Dentre eles estão o "Capitão 7" criado por Rubem Biá, que fora para a TV Record em forma de seriado, em 1954, e migrado para as HQs em 1959, contava a história do menino Carlos, levado por alienígenas até o Sétimo Planeta, de onde veio seu nome e teve seu corpo e mente aprimorados, voltando, já adulto, a Terra. Seus poderes dependem não só de seu corpo, mas também de seu uniforme e se assemelham bastante aos do Super-Homem; “Capitão Estrela” (1961), de Juarez Odilon, fez o mesmo caminho do "Capitão 7" (figura 16), da TV para as revistas. "Capitão Estrela" era patrocinado pela empresa de brinquedos Estrela, servindo como divulgador da marca. Tinha um fiel companheiro chamado Menino Brazil e durou apenas oito números; "Vigilante Rodoviário" (1952), de Ary Fernandes (figura 17), migrou para as HQs em 1961, contava as histórias de um policial rodoviário que combatia o crime com a ajuda de seu cão, Lobo, uma Harley Davidson e um Simca Chambord (MOYA, 1996). Muitos heróis brasileiros surgiram nessa época, todos de vida curta.

Então veio a ditadura militar em 1964. A censura teve impacto nas histórias em quadrinhos, tirando os personagens de Ziraldo de circulação. Desde então o underground brasileiro se desenvolveu com o mesmo Ziraldo, Miguel Paiva, Jaguar, Cláudio Paiva, Henfil e muitos outros que, de forma subjetiva ou não, procuravam criticar o subdesenvolvimento militar do país. Em 1969 foi criado O Pasquim (figura 18), uma publicação de oposição à ditadura que utilizava de quadrinhos de entretenimento e humor para abordar assuntos bastante sérios (QUEIROZ, 2008). 


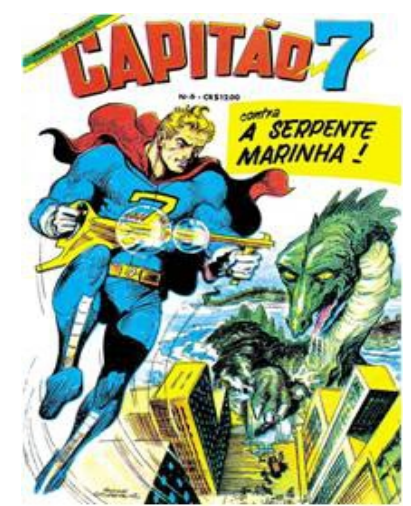

Figura 16 - Capa de Capitão 7

Fonte: Guia dos Quadrinhos, 2011

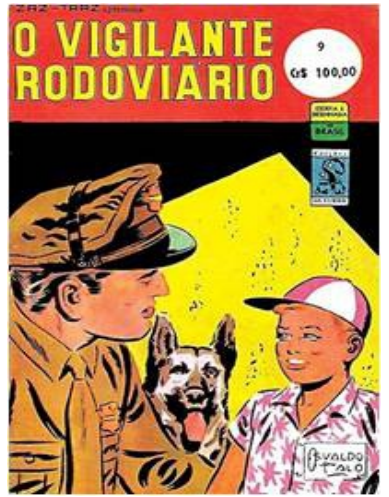

Figura 17 - Capa de Vigilante Rodoviário

Fonte: Guia dos Quadrinhos, 2011

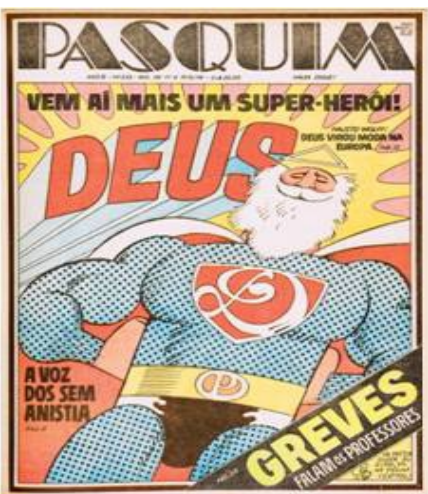

Figura 18 - Capa de Pasquim

Fonte: Ziraldo, 2010

Os super-heróis sumiram e as histórias de terror ganharam mais espaço. 0 império de Maurício de Sousa só aumentava, enquanto Mônica se tornava seu personagem central. Assim aconteceu até os anos 1980. Da mesma forma que seriados migravam para as HQs nos anos anteriores, programas de TV em geral começaram a ganhar suas versões em quadrinhos, como Xuxa, Os Trapalhões, Sérgio Mallandro, TV Colosso, entre outros.

As publicações de histórias em quadrinhos no Brasil foram, em quantidade, bem superiores às descritas acima, porém os períodos chave, importantes para a contextualização e compreensão do desenvolvimento das HQs no país se fazem presentes.

\section{CONCLUSÃO}

Dos anos de 1990 até hoje muitos quadrinistas brasileiros, principalmente desenhistas, vêm também produzindo nacionalmente ou trabalhando para grandes editoras americanas (Marvel, DC, Image, Dark Horse). Alguns destes já foram reconhecidos com prêmios no exterior, como os prêmios Eisner entregues a Fábio Moon e Gabriel Bá na categoria de Melhor Minissérie por Daytripper; e Rafael Albuquerque em Melhor Nova Série por Vampiro Americano (COMIC-CON, 2012). Nota-se que há um amadurecimento da indústria das HQs no país e que os designers, como comunicadores de ideias, possam se aproximar dela para que aumente suas possibilidades de meios de comunicação .

Por meio da presente revisão bibliográfica e documental descritiva, o design pode compreender melhor o desenvolvimento das histórias em quadrinhos no Brasil, para que possa ser estimulado a dialogar com essa linguagem em quaisquer projetos de comunicação que possa utilizar textos e imagens. Considerase que a apresentação deste desenvolvimento, ainda que pequena, possa aumentar o embasamento sobre de onde veio e onde está a comunicação das HQs nos dias de hoje. E ainda, que a sua base possa oferecer recursos para o desenvolvimento de projetos de design que se utilizam de quadrinhos.

Observa-se, portanto, que se mostra de grande valia uma aproximação mais efetiva entre design e as histórias em quadrinhos, tendo em vista que ambas trabalham com processos de criação semelhantes e utilizam de linguagens específicas que se relacionam de forma bastante direta com a cultura e a contexto de 
cada tempo.

\section{REFERÊNCIAS BIBLIOGRÁFICAS}

ADG BRASIL - Associação dos Designer Gráficos do Brasil. Sobre: o que é design gráfico? Disponível em: <http://www.adg.org.br/adgbrasil.php>. Acesso em 20/08/2011.

ADIDAS FOOTBALL. Graphic Novel Kaká. Disponível em <http://www.adidas.com/campaigns/footballss09/content/?adidas_cc=br\#/etn/graphic_novel/kaka>. Acesso em 20/08/2011

BOER, Gustavo de, BONINI, Luiz Alberto. Design thinking: uma nova abordagem para inovação. In Biblioteca Terra Forum. Disponível em <http://biblioteca.terraforum.com.br/Paginas/designthinking.aspx>. Acesso em 05/08/2011.

CAMARGO, Mário de. Gráfica - Arte e Indústria no Brasil. São Paulo: Bandeirantes Gráfica, 2003.

CIRNE, Pedro. Will Eisner, o "Dom Quixote" das histórias em quadrinhos. In UOL Entretenimento. Disponível em <http://entretenimento.uol.com.br/ultnot/2005/01/04/ult100u1587.jhtm>. Acesso em 05/08/2011.

COMIC-COM. Wilson and Dapper Men Tie for Best Graphic Album at 2011 Eisner Awards. Disponível em: <http://www.comic-con.org/cci/cci_eisners_11win.php\#list>. Acesso em 10/02/2012.

FERREIRA, João Paulo Mesquita Hidalgo; FERNANDES, Luiz Estevam de Oliveira. 0 "pai dos pobres": o mito Getúlio Vargas. 2004. Disponível em:

<http://www.ciadaescola.com.br/zoom/materia.asp?materia=235\&pagina=7>. Acesso em 05/08/2011.

GIBIOSFERA. Gibi: você sabe qual a origem desta palavra? 2010. Disponível em:

<http://www.gibiosfera.com.br/blog/2010/02/gibi-origem-palavra/>. Acesso em 05/08/2011.

GIL, Antonio Carlos. Métodos e técnicas de pesquisa social. São Paulo: Atlas, 1999.

GOOGLE CHROME TEAM. Google Chrome - Words by the Google Chrome team, comics adaptation by Scott McCloud. Disponível em <http://www.google.com/googlebooks/chrome/>. Acesso em 20/08/2011.

GRAND COMIC DATABASE. Capitão 7, no 6, 2011. Disponível em

$<$ http://www.guiadosquadrinhos.com/edicao.aspx?cod_tit=ca213100\&esp=\&cod_edc=31984>. Acesso em $20 / 08 / 2011$.

. 0 vigilante rodoviário, no 9, 2011. Disponível em

<http://www.guiadosquadrinhos.com/edicao.aspx?cod_tit=vi213100\&esp=\&cod_edc=31684>. Acesso em 20/08/2011.

GUIA EBAL. Ciência em Quadrinhos. 2011. Disponível em <http://guiaebal.com/cienciaquadrinhos.html>. Acesso em 20/08/2011.

20/08/2011.

Grandes Figuras. 2011. Disponível em <http://guiaebal.com/grandesfigura.html>. Acesso em 20/08/2011.

Série Sagrada. 2011. Disponível em <http://guiaebal.com/sagrada01.html>. Acesso em

EISNER, Will. Narrativas Gráficas. São Paulo: Martins Fontes, 2005.

. Quadrinhos e Arte Seqüencial. São Paulo: Martins Fontes, 2006.

JUNIOR, Gonçalo. A guerra dos gibis: a formação do mercado editorial brasileiro e a censura aos quadrinhos, 1933-64. São Paulo: Companhia das Letras, 2004.

MAGNO, Simone. Evento marca os 50 anos da turma do Pererê. 2010. Disponível em:

$<$ http://colunas.cbn.globoradio.globo.com/platb/tempodeletras/2010/10/22/evento-marca-os-50-anosda-turma-do-perere/>. Acesso em 05/08/2011.

MCCLOUD, Scott. Desenhando Quadrinhos. São Paulo: M. Books, 2007.

Desvendando os Quadrinhos. São Paulo: M. Books, 2004. 
Michigan State University Libraries Digital \& Multimedia Center. Les amours de Mr. Vieux Bois [electronic resource]. Disponível em

<http://magic.lib.msu.edu/search S39?/cNC1659+.T67+1839/cnc+1659+t67+1839/1\%2C2\%2C2\%2CB/fr ameset $\& F F=c n c+1659+t 67+1839+$ online $\& 1 \% 2 C 1 \% 2 C>$. Acesso em 20/08/2011.

MINZESHEIMER, Bob. 9/11 gets a graphic retelling. USA TODAY Updated 8/22/2006. Disponível em: $<$ http://www.usatoday.com/life/books/news/2006-08-21-9-11-report-book_x.htm>. Acesso em 20/08/2011.

MIRANDA, André. Biblioteca Nacional sofre com furtos de importantes obras de seu acervo e compra de material superfaturado Disponível em: <http://oglobo.globo.com/cultura/mat/2011/05/28/bibliotecanacional-sofre-com-furtos-de-importantes-obras-de-seu-acervo-compra-de-material-superfaturado924556619.asp>. Acesso em: 28/08/2011.

MOYA, Álvaro de. História da história em quadrinhos. São Paulo: L \& PM, 1987.

. SHAZAM!. São Paulo: Perspectiva, 1977.

O MUNDO DE CARLOS ZÉFIRO. Instituto Nacional de Quadrinhos Eróticos. 2011. Disponível em <http://www.carloszefiro.com/capas3.php>. Acesso em 20/08/2011.

QUEIROZ, Andréa C. de B. O Pasquim: Embates Entre a Cultura Política Autoritária e a Contracultura. Revista Eletrônica Cadernos de História, vol. VI, ano 3, n. 2, dezembro de 2008. Disponível em <http://www.ichs.ufop.br/cadernosdehistoria>. Acessado em 2 de ago/08/2011.

RABELO; Giani. VIRTUOSO, Tatiane dos Santos. Cartilha Getúlio Vargas para crianças: produzindo efeitos sobre a infância. V Seminário Estadual Arte na Educação. Criciúma, set. 2008. Disponível em: <http://www.gedest.unesc.net/seilacs/cartilhagetuliovargas_giani.pdf>. Acesso em 20/08/2011.

SAN FRANCISCO Academy of Comic Art Collection, The Ohio State University Library Research Cartoon. The Yellow Kid. Disponível em: <http://cartoons.osu.edu/yellowkid/1897/1897.htm>. Acesso em 05/08/2011.

SOUZA, Maurício de. Crônica 234 - Bidu primeiro e único. 2001. Disponível em: <http://www.monica.com.br/mauricio/cronicas/cron234.htm>. Acesso em 05/08/2011.

ZIRALDO. Pasquim - o novo herói. Disponível em: < http://ziraldo.blogtv.uol.com.br/2010/01/26/pasquim-o-novo-heroi>. Acesso em 28/08/2011. 